\title{
Propionate Inhibition of Succinate:CoA Ligase (GDP) and the Citric Acid Cycle in Mitochondria
}

\author{
DAVID A. STUMPI: JOHN MCAFEE. JANICE K. PARKS, ANI) LUIS EG JUEN \\ University of Colorado Health Sciences (ir. Denver. Colorado. US.A
}

Summary

\begin{abstract}
Propionate inhibits oxygen consumption by rat liver mitochonIria when glutamate, $\alpha$-ketaglutarate, and succinate are substrates. Carnitine prevents this effect. The pattern of inhibition of ${ }^{4} \mathrm{CO}_{2}$ release from metabolic intermediates indicates citric acid cycle inhibition between succinate:coenzyme $A(\mathrm{CoA})$ ligase (FDP) and malate dehydrogenase. Propionyl $\mathrm{COA}$ is synthesized from propionate in mitochondria. Propionyl COA is a potent inhibitor of succinate:CoA ligase with positive cooperativity and half-maximal inhibition at $2 \times 10^{-4} \mathrm{M}$ propionyl CoA.
\end{abstract}

\section{Speculation}

Inhibition of oxidative phosphorylation and the citric acid cycle may produce the Reye's-like syndrome which occurs in propionic acidemia and possibly related organic acid or mitochondrial disorders. Mitochondrial acyl coenzyme $A$ may be increased in these patients and respond favorably to carnitine therapy.

Propionic acidemia is a rare inborn error of lipid and amino acid catabolism (21). It occasionally produces a toxic encephalopathy resembling Reye's syndrome (26). Reye's syndrome probably results from disrupted mitochondrial metabolism (5). Similar metabolic abnormalities occur in propionic acidemia and mitochondrial disorders (26), including hyperammonemia, lactic acidosis. hypoglycemia, and ketosis. Understanding the effects of propionic acid on mitochondrial metabolism might, therefore, clarify the pathophysiology of the associated abnormalities in propionic acidemia and be relevant to Reye's syndrome and other mitochondrial disorders.

\section{METHODS}

Mitochondria were prepared from rat liver and polarographic assays performed as previously described (27). Propionate was preincubated with mitochondria for $4.5 \mathrm{~min}$ at $30^{\circ} \mathrm{C}$ before addition of other reagents; controls were preincubated without propionate. A final propionate concentration of $4.76 \mathrm{mM}$ was used in standard assays. ${ }^{14} \mathrm{C}$-Labeled compounds were added (final concentration. $3.3 \mathrm{mM}$ ) after preincubation as above with additional incubation at $30^{\circ} \mathrm{C}$ for $15 \mathrm{~min}$ and ${ }^{14} \mathrm{CO}$. collection as previously reported (28). For the decarboxylation studies, the polarographic assay mixture was supplemented with ADP (final concentration, $3.3 \mu \mathrm{M}$ ), glucose (final concentration, $33 \mu \mathrm{M}$ ), and yeast hexokinase (Sigma Chemical Co., St. Louis, MO: $1.9 \mathrm{IU} / 0.3 \mathrm{ml}$ assay volume) to maintain state 3 rates during incubation. Ascorbate and $N, N, N^{\prime}, N^{\prime}$-tetramethyl-p-phenylenediamine were used as previously described (30). Succinate:coenzyme A (CoA) ligase (GDP) (EC 6.2.1.4) assays had in final concentrations: $0.1 \mathrm{mM}$ GDP. 0.1 $\mathrm{mM}$ succinyl $\mathrm{CoA}$, and $10 \mathrm{mM} \mathrm{MgCl}: 2$ in $100 \mathrm{mM}$ phosphate buffer ( $\mathrm{pH} 7.4$ ). Assays for the reverse reaction contained $0.1 \mathrm{mM}$ (iTP, $0.1 \mathrm{mM}$ COA. $10 \mathrm{mM} \mathrm{MgCl}$, and $10 \mathrm{mM}$ succinate in 100 $\mathrm{mM}$ 4-(2-hydroxyethyl)-1-piperazineethanesulfonic acid buffer ( $\mathrm{pH} 7.4$ ). Thioester concentration was followed at $235 \mathrm{~nm}$ with a Beckman model 25 recording spectrophotometer at $30^{\circ} \mathrm{C}$ during the initial several min when linearity with time was observed. Enzyme concentration was adjusted to maintain initial rates of less than $0.04 \mathrm{~A}$ units $/ \mathrm{min}$. The reaction was initiated by addition of enzyme after a stable. flat baseline was obtained. The difference of molar absorptivities between succinyl ( $O A$ and ( $O A$ under these conditions is $4.0 \mathrm{mM} \mathrm{cm} \mathrm{(4).} \mathrm{Purified} \mathrm{pig} \mathrm{heart} \mathrm{succinate:}$ (OA ligase ( $\mathrm{SCL}$ ) was purchased from Sigma Chemical ${ }^{\circ} \mathrm{O}$. for use in the kinetic analyses. Statistical and Michaelis-Menton enzyme kinetic analyses match those used previously (29). Hill plots (7) were evaluated by linear regression analysis. Propionic acid was neutralized with $\mathrm{NaOH}$ or $\mathrm{KOH}$ before use in all these experiments.

\section{RESULTS}

Propionate inhibited state 3 rates and slightly stimulated state 4 rates of oxygen consumption (Table 1). Both these effects contributed to a decreased respiratory control ratio (RCR) (Table 2 ). These effects were observed with glutamate, $\alpha$-ketoglutarate. and succinate. There was no alteration of ADP:O ratios. despite the reduced $R C R$ (Table 2 ). Carnitine, when preincubated with propionate, prevented or minimized these effects of propionate. This carnitine effect was variable and sometimes only seen at lower propionate concentrations. Carnitine did not reverse the effects of propionate in the short time (about $1 \mathrm{~min}$ ) available after assessing the primary effect of propionate. These effects of propionate are illustrated in a representative set of experiments (Fig. 1). Propionate effects on other substrates suitable for polarographic assays. including pyruvate:malate and palmitylcarnitine. could not be as accurately assessed because of the poor RCR: that occurred in control runs after the 5 min preincubation.

Preincubation of mitochondria with propionate was necessary for consistent, maximal inhibition of state 3 rates. Following a preincubation of mitochondria and maximal inhibition of state 3 rates, subseyuently added mitochondria are not immediately affected. There was a variation in the susceptibility of mitochondria. The relatively high propionate concentration was used because all preparations were affected at this level. Some mitochondrial preparations were affected at propionate concentrations as low as 0.4 $\mathrm{mM}$.

Carbon dioxide release from $\left[1-{ }^{14} \mathrm{C}\right]$ pyruvate, $\left[2-{ }^{14} \mathrm{C}\right]$ pyruvate. $\left[6-{ }^{14} \mathrm{C}\right]$ citrate, and $\left[1-{ }^{14} \mathrm{C}\right] \alpha-$ ketoglutarate was not significantly inhibited by propionate. In contrast. ${ }^{14} \mathrm{CO}$, release from $\left[1,4-{ }^{14} \mathrm{C}\right]$ succinate, $\left[U-{ }^{1+} \mathrm{C}\right]$ glutamate, and $\left[U_{-}{ }^{14} \mathrm{C}\right]$ malate was inhibited by propionate (Table 3 ).

SCL was inhibited by propionyl CoA. Inhibition at low propionyl CoA concentrations appeared to be simple noncompetitive on $1 / \mathrm{s}$ versus $1 / \mathrm{v}$ plots with $K_{1}$ of 0.1 to $0.3 \mathrm{mM}$. At higher 
Table 1. Effect of propionate on state 3, state 4, and N.N.N',N'-tetramethyl-p-phenylenediamine: ascorbate rates of oxygen consumption

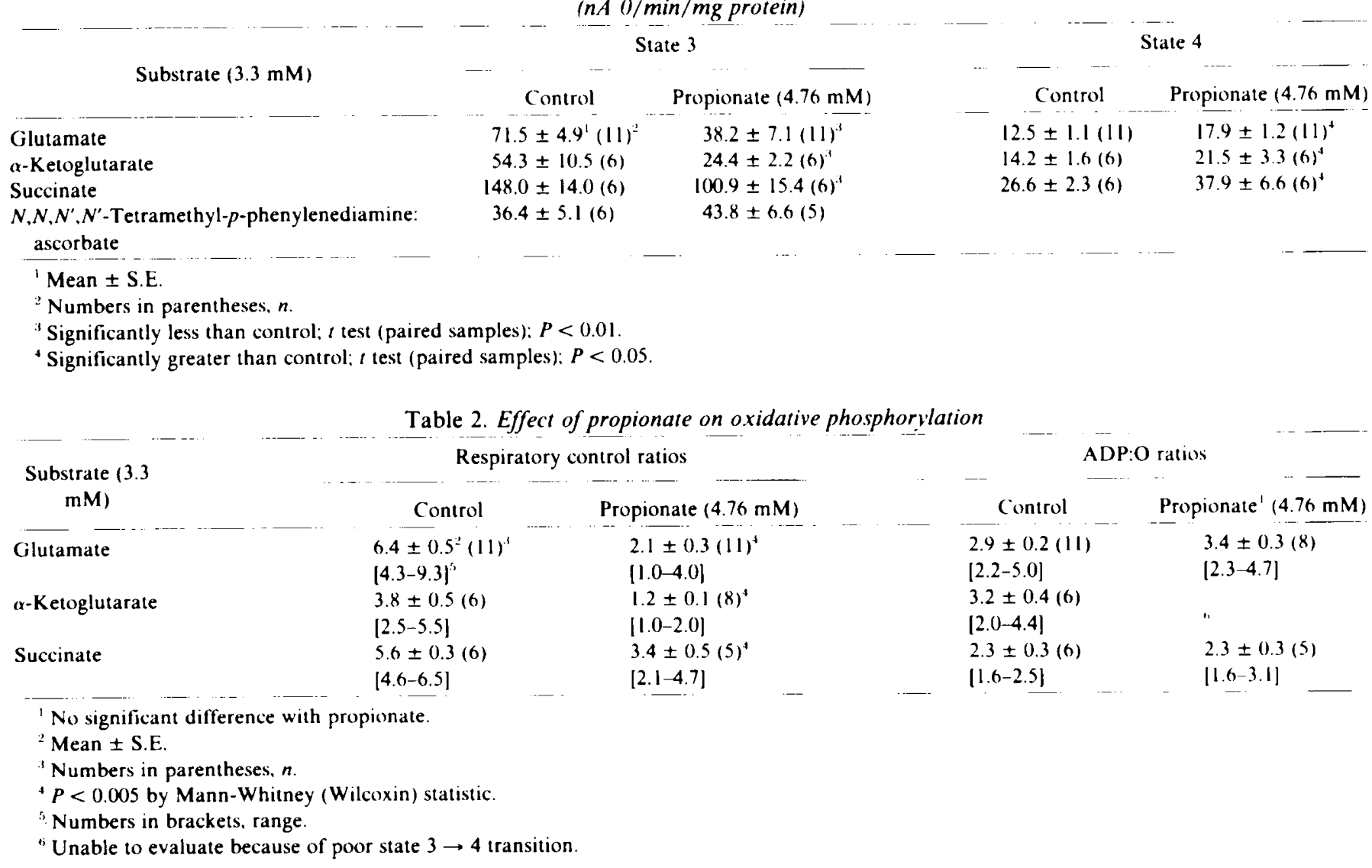

propionyl CoA concentrations, this plot was concave upward, indicating a different mechanism of inhibition. The Dixon plot ( $\mathrm{i}$ versus $1 / \mathrm{v}$ ) was also nonlinear (Fig. 2). The Hill plots were linear (Fig. 3) with a Hill coefficient $(n)$ of $3.29 \pm 0.26$ (mean \pm S.E.; 6 determinations) and half-maximal inhibition at $246 \pm 27 \mu \mathrm{M}$ (calculated from $\log \frac{V_{i}}{V_{0}-V_{i}}=O$ intercept). Propionic acid and propionyl CoA were not substrates for the enzyme when added to the reaction mixture in place of succinate or succinyl CoA, nor did propionate affect enzyme activity. Typical Michaelis-Menton kinetics were obtained in the absence of propionyl CoA with a succinyl CoA $K_{m}$ of $23 \mu \mathrm{M}$ and succinate $K_{m}$ of $313 \mu \mathrm{M}$ in the forward and reserve reactions, respectively.

Several other acyl CoA derivatives were evaluated for similar effects on SCL. These limited experiments, one or 2 Hill plots per compound, are included for completeness (Table 4) but must be viewed with caution until more extensive investigations are available.

\section{DISCUSSION}

Propionyl CoA inhibition of SCL may explain the impaired oxidative metabolism produced by propionate. Many features of propionic acidemia may relate to this effect. Levels of this inhibitor are probably reduced by carnitine in vitro, suggesting a clinical therapeutic modality.

Maximal effects occur with preincubation, implying inhibition by a metabolic product or depletion of vital compounds. Inhibitor is in the matrix rather than the incubation media because subsequently added mitochondria are unaffected. Addition of propionate to mitochondria increases propionyl $\mathrm{CoA}$ and reduces free CoA and acetyl CoA (25).

${ }^{14} \mathrm{CO}_{2}$ release from $\left[1-{ }^{14} \mathrm{C}\right]$ pyruvate, $\left[2-{ }^{14} \mathrm{C}\right]$ pyruvate, $\left[6-{ }^{14} \mathrm{C}\right] \mathrm{cit}-$ rate, and $\left[1-{ }^{14} \mathrm{C}\right] \alpha$-ketoglutarate occurs between the pyruvate dehydrogenase complex (PDHC) and succinyl CoA formation and is not inhibited by propionate. Complete release of ${ }^{14} \mathrm{CO}$, from $\left[1,4-{ }^{14} \mathrm{C}\right]$ succinate, $\left[U-{ }^{14} \mathrm{C}\right]$ glutamate, and $\left[U{ }^{14} \mathrm{C}\right]$ malate require: more than one turn through the citric acid cycle, and decarbox. ylation of these compounds is inhibited by propionate. Thi: indicates that inhibition is between SCL and malate dehydrogen. ase (EC 1.1.1.37).

Propionyl CoA is an inhibitor of SCL with positive cooperativ ity. The Hill coefficient suggests 4 propionyl CoA-binding site: per mole of enzyme. Cooperativity can be due to allosteric inter actions or, particularly with multisubstrate enzymes, to othe mechanisms (7). No allosteric regulation was recognized in othe studies, but they did not include propionyl CoA (17).

Other acyl CoA derivates are approximately equipollent it inhibiting SCL. The concentrations required are similar to thosi affecting pyruvate carboxylase (EC 6.4.1.1) (24), succinyl CoA:3 oxoacid transferase (EC 2.8.3.5) (6), carbamylphosphate synthe tase (9), and the glycine cleavage system (15).

Free CoA also affects SCL. Hill coefficients and half-maxima inhibition concentrations are such that at low concentrations $C o f$ has a modest effect, and propionyl $\mathrm{COA}$ is without effect. A higher concentrations, propionyl COA is a more potent inhibito than an equivalent amount of $\mathrm{COA}$. Thus, if total $\mathrm{CoA}$ (free plu propionyl) is constant and the effects are additive, SCL is inhibiter as the proportion of $\mathrm{COA}$ in the propionyl $\mathrm{COA}$ form is increased

High acyl CoA levels may regulate citric acid cycle flux. Positivi cooperativity optimizes regulatory potential by providing : "chemical switch" that turns off an enzyme at a critical inhibito concentration. In patients with organic acidemias, this can resul in catastrophic effects when high acyl CoA levels are the result o their metabolic block rather than reflecting their overall metaboli status.

Propionyl COA inhibits the PDHC (2), and propionate inhibit state 3 rates of oxygen consumption with pyruvate as substrat (34). This oxygen consumption depends not only on NADF generated by the PDHC but, to a large degree, on subsequen 

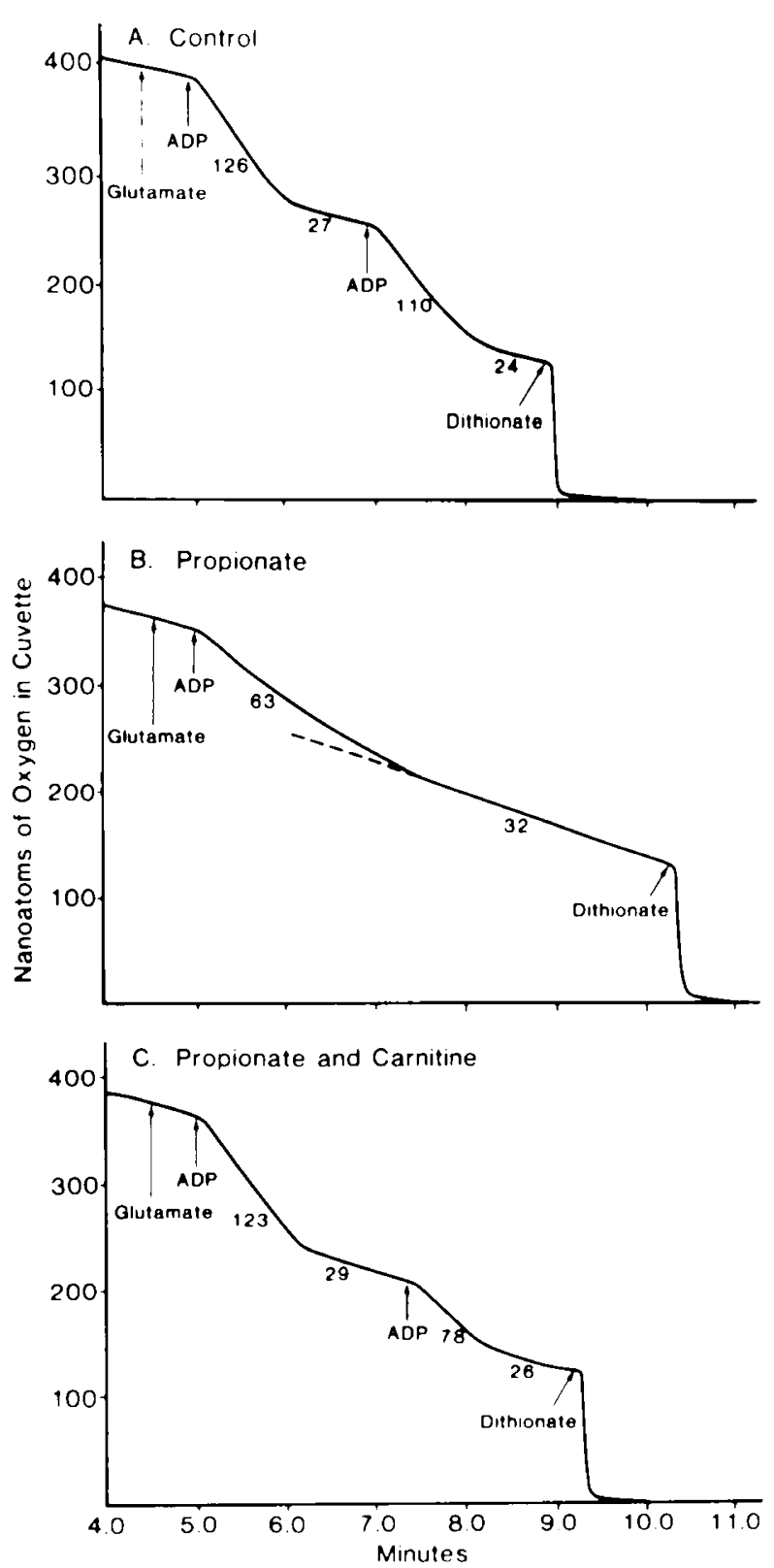

Fig. I. Effect of propionate on oxygen consumption. Mitochondria were preincubated for $4.5 \mathrm{~min}$ with no additions $(A)$, with $4.76 \mathrm{mM}$ propionate $(B)$, or with $4.76 \mathrm{mM}$ propionate: $5 \mathrm{mM}$ carnitine $(C)$. Propionate inhibited the state 3 rate and lowered the $R C R$. Carnitine prevented this effect. Numbers below lines, oxygen consumption in $\mathrm{nA} / \mathrm{min} / \mathrm{mg}$ protein

oxidative reactions in the citric acid cycle. We observed no effect on $\left[1-{ }^{14} \mathrm{C}\right]$ pyruvate decarboxylation although we used concentrations of propionate sufficient to inhibit oxygen consumption with pyruvate (34). Also, decarboxylation of $\left[2-{ }^{19} \mathrm{C}\right]$ pyruvate via acetyl CoA was not affected, indicating that reduced oxygen consumption is not due to depletion of CoA or inhibition of the PDHC.

Serum propionate levels reach $5 \mathrm{mM}$ in propionic acidemia (21). Infusion of propionate at this concentration produces tissue levels of about $50 \mu \mathrm{M}$ propionyl $\mathrm{CoA}(20,25)$. Mitochondrial levels are probably higher, particularly in the human disorder where propionate is derived from mitochondrial propionyl CoA. Concentrations used in our studies approximate those encountered in clinical situations.

Inhibition of the citric acid cycle would impair energy generation and the catabolism of many substrates. Propionate inhibits ureagenesis (8), and hyperammonemia might result from an en- ergy deficiency state (30) or the inhibition of carbamylphosphate synthetase by propionyl CoA (9). Impaired flux through the citric acid cycle might contribute to the lactic acidosis and ketosis because catabolism of these compounds requires the citric acid cycle.

Table 3. The effect of propionate on the decarboxylation of

\begin{tabular}{|c|c|c|}
\hline (Compound $(3.3 \mathrm{mM})$ & Control & Propionate $(4.76 \mathrm{mM})$ \\
\hline [1.-14(]Pyruvate & $10.30 \pm 2.01^{2}(8)^{3}$ & $8.01 \pm 1.50(8)$ \\
\hline [2-1.'C]Pyruvate & $0.47 \pm 0.13(7)$ & $0.34 \pm 0.12(7)$ \\
\hline$U^{-14}$ ( ) Palmitate & $0.48 \pm 0.13(6)$ & $0.35 \pm 0.08(6)$ \\
\hline |6- $-^{1.4}()^{\prime}$ 'itrate & $2.39 \pm 0.38(6)$ & $2.41 \pm 0.43(6)$ \\
\hline [1- ${ }^{14}(\mathrm{C} \mid a-K e t o g l u t a r a t e$ & $8.00 \pm 1.84$ & $5.44 \pm 1.10(5)$ \\
\hline | $U-{ }^{1.4}($ Cilutamate & $3.13 \pm 0.50(8)$ & $1.17 \pm 0.16(8)^{4}$ \\
\hline$\left[1.4-^{14} \mathrm{C} \mid\right.$ Succinate & $3.43 \pm 0.64(7)$ & $1.68 \pm 0.38(7)^{4}$ \\
\hline [U-14 $C$ Malate & $0.98 \pm 0.19(5)$ & $0.28 \pm 0.03(4)^{5}$ \\
\hline
\end{tabular}

' nmoles/min/mg protein.

${ }^{2}$ Mean \pm S.E.

Numbers in parentheses, $n$.

' $P<0.02: t$ test, unpaired samples.

$P<0.01$ : Mann-Whitney (Wilcoxin) statistic.

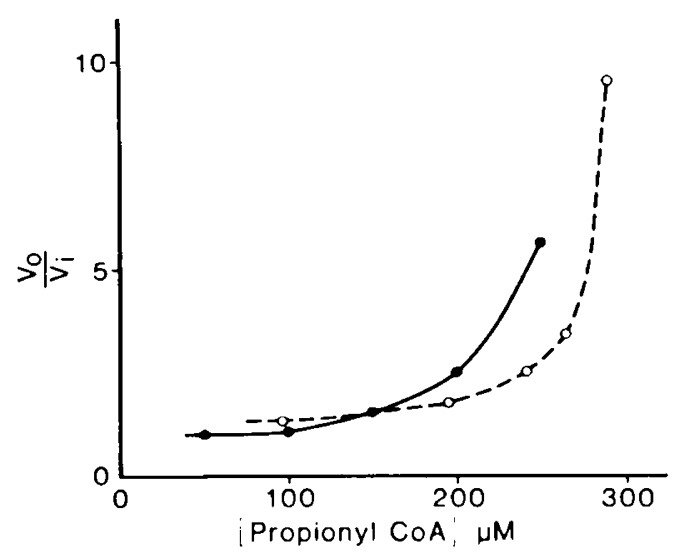

Fig. 2. Dixon plot. Positive cooperativity between inhibitor molecules is demonstrated. Effect of propionyl COA on succinyl COA formation (Q) and disappearance $(O)$ is shown.

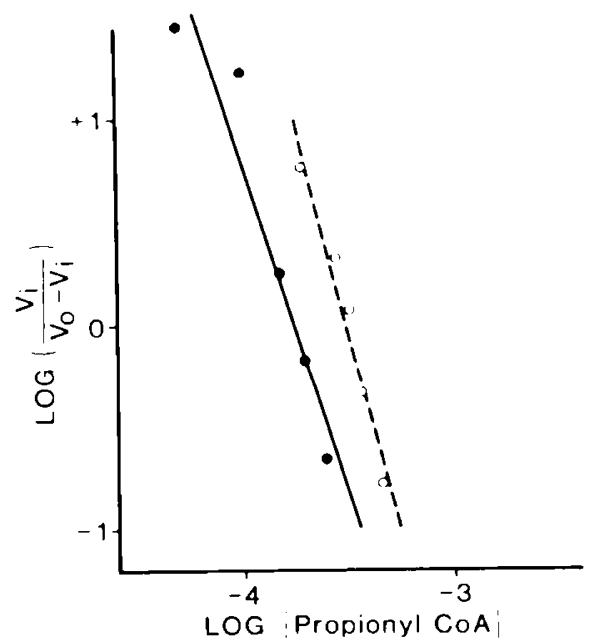

Fig. 3. Hill plot for propionyl $\mathrm{COA}$ inhibition of succinate:CoA ligase (GDP). Linearity is observed in measuring the effect of propionyl CoA on succinyl CoA formation (O) and disappearance (O). Data are plotted according to the relationship: $\log \frac{\mathrm{V}_{1}}{\mathrm{~V}_{11}-\mathrm{V}_{1}}=\log \mathrm{K}-n \log$ Ipropionyl

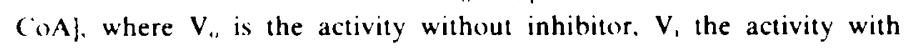
propionyl CoA, and $n$ is the Hill coefficient. 
Table 4. Acyl CoA inhibition of succinate: CoA ligase

\begin{tabular}{lcc}
\multicolumn{1}{c}{ Compound } & $\begin{array}{c}\text { Half-maximal inhibi- } \\
\text { tion }(\mu \mathrm{M})^{*}\end{array}$ & Hill coefficient \\
Propionyl CoA & $246 \pm 27^{3}(6)^{4}$ & $3.29 \pm 0.26(6)$ \\
Acetyl CoA & 272.283 & 3.50 .2 .71 \\
Tiglyl CoA & 114,113 & $2.02,1.16$ \\
Methylmalonyl CoA & 303 & 3.52 \\
Glutaryl CoA & 264 & 3.21 \\
Butyryl CoA & 274 & 3.21 \\
Crotonyl CoA & 173 & 2.26 \\
Free CoA & $349 \pm 16(4)$ & $2.27 \pm 0.12(4)$ \\
\hline
\end{tabular}

'None of the acyl CoA compounds were substrates. Assay at saturating (97 $\mu \mathrm{M}$ ) succinyl CoA and following its disappearance.

${ }^{2}$ Hill plot $\log \left(\frac{V_{1}}{V_{n}-V_{i}}\right)=O$ intercept. calculated by linear regression analysis.

Mean \pm S.E.

${ }^{4}$ Numbers in parentheses, $n$.

Hyperglycinemia in propionic acidemia may result from inhibition of the glycine cleavage system (11,31). Alternatively, acyl CoA derivatives may affect the succinate-glycine cycle. This proposed cycle remains poorly defined. $\delta$-Aminolevulinic acid synthetase initiates the cycle; succinyl $\mathrm{COA}$ and glycine condense, releasing $\mathrm{CO}_{2}$. Subsequent reactions form $\gamma, \delta$-dioxovaleric acid and $\alpha$-ketoglutaraldehyde $(14,19)$. It is not clear whether succinyl CoA is reformed from succinate (via SCL) or from $\alpha$-ketoglutarate (via its dehydrogenase). If the former is the case, then our results may provide an explanation for the hyperglycinemia in propionic acidemia. Our results may also have significance to patients with acute intermittent porphyria because crises are related to increased $\delta$-aminolevulinic acid synthetase activity and changes in $\gamma, \delta$-dioxovalerate excretion (14).

Fatty liver in propionic acidemia indicates impaired catabolism of fatty acids. Inhibition of palmitate decarboxylation in our study did not reach statistical significance, but did in another investigation (8). Low concentrations of propionate $(0.5 \mathrm{mM})$ reduced acetyl $C O A$ and acetyl carnitine formation apparently by inhibiting fatty acid activation or $\beta$-oxidation because propionate does not inhibit acetyl CoA synthetase (EC 6.2.1.1), deplete available carnitine, or accelerate acetyl $\mathrm{CoA}$ removal by citrate synthase (EC 4.1.3.7) at these low concentrations (20). Activation of fatty acids occurs by three mechanisms. High propionate concentrations may impair activation outside the matrix to a carnitine derivative by sequestering carnitine as a propionyl derivative. Activation also occurs in the matrix by either an ATP- or GTP-dependent acyl CoA synthetase (EC 6.2.1.3). The ATP-dependent acyl CoA synthetase produces AMP, and the only mechanism for converting AMP back to ADP in the matrix is by the GTP-AMP transphosphorylase (EC 2.7.4.10) (10). Therefore, both matrix-activating enzymes rely on GTP. The major sources of matrix GTP are SCL and ATP:nucleosidediphosphate phosphotransferase (EC 2.7.4.6) (16). Thus, oxidation of citric acid cycle substrates and fatty acids are mutually controlled (22). Inhibition of SCL by propionyl CoA could reduce matrix GTP and fatty acid activation. Low matrix GTP could contribute to the fatty liver in propionic acidemia. Low matrix GTP could also impair gluconeogenesis because the GTP-dependent gluconeogenic enzyme phosphoenolpyruvate carboxykinase (EC 4.1.1.32) is located in the mitochondrial matrix in man.

Propionyl CoA can be readily converted to propionylcarnitine in liver (1). At high propionate concentrations ( $4 \mathrm{mM}$ in infusates). free carnitine is reduced to $10 \%$ of control in liver (20). This might account for the protective effect of added carnitine in our system. This observation might be relevant to the treatment of patients with propionic acidemia. Carnitine has been administered safely in other clinical situations $(13,23)$ and might ameliorate symptoms in propionic acidemia by reducing levels of toxic propionyl CoA.
Carnitine may prevent the adverse metabolic effects of othe organic acids $(3,12)$.

Our results may be important to other organic acid disorder including methylmalonic aciduria, $\beta$-ketothiolase deficiency, an glutaric aciduria. Also, levels of short- and medium-chain organi acids are significantly elevated in serum of Reye's syndrom. patients $(18,32,33)$. Future studies of these disorders migh include assays of acyl CoA tissue and mitochondrial concentra tions. Direct assay of SCL may not be useful because acyl Cof derivatives would be diluted in preparing tissues for $\mathrm{SCL}$ assay.

\section{REFERENCES AND NOTES}

1. Bohmer. T.. and Bremer, J.: Propionylcarnitine physiological variations in vive Biochim. Biophys. Acta, 152: 559 (1968).

2. Bremer. J.: Pyruvate dehydrogenase, substrate specificity and product inhibition Eur. J. Biochem., \&: 535 (1969)

3. Brendel, K.. and Brassler. R.: Mechanism of inhibition of gluconeogenesis by 4 pentenoic acid. Am. J. Clin. Nutr.. 23: 972 (1970).

4. (ha, S., and Parks. R. E.. Ir.: Succinic thiokinase. I. Purification of the enzym from pig heart. J. Biol. (hem., 239: 1961 (1964).

5. DeVivo. D. ( $\therefore$ Reye syndrome: a metabolic response to an acute mitochondria insult? Neurology. 28: 105 (1978).

6. DeVivo. D. C.. and Obert. K. A.: Inhibition of succinyl-CoA: 3-oxoacid trans ferase hy coenzyme A analogues. Trans. Am. Soc. Neurochem. 10): 225 (1979

7. Fromm. H. J.: Initial Rate Enzyme Kinetics. p. 236 (Springer-Verlag. Berlir 1977).

8. Glascow. A. M., and Chase. H. P.: Effect of propionic acid on fatty acid oxidatio and ureagenesis. Pediatr. Res., 10: 683 (1976).

9. Gruskay. J. A.. and Rosenberg. L. E.: Inhibition of hepatic mitochondria carbamyl phosphate synthetase (CPSI) by acyl coA esters: possible mecha nisms of hyperammonemia in the organic acidemias. Pediatr. Res.. 1.3: 47 (1979).

10. Heldt. H. W.. and Schwalback, K.: The participation of GTP-AMP-P transferas in substrate level phosphate transfer of rat liver mitochondria. Eur. J. Biochem l: $199(1967)$

11. Hillman. R. E., and Otto. E. F.: Inhibition of glycine-serine interconversion i cultured human fibrohlasts by products of isoleucine catabolism. Pediatr. Res 8: 941 (1974)

12. Holland. P. (.. and Sherratt. H. S. A.: Biochemical effects of the hypoglycemi compound pent-4-enoic acid and related non-hypoglycemic tatty acids. Bio chem. J., l.36: 157 (1973).

13. Karpati. G.. Carpenter, S.. Engel, A. G.. Watters. G.. Allen. J., Rothman. S Klassen, $(j .$. and Mamer, O. A.: The syndrome of systemic carnitine deficiency Clinical. morphological, biochemical, and pathophysiological features. Neu rology, 25: 16 (1975).

14. Kissel. H. J. Heilmeyer. 1.. M. (3.. Jr. and Heilmeyer. 1.: Ixcretion of $\gamma \delta$ dioxovalerinic acid and $\delta$-aminolaevulinic acid in various disorders of haen synthesis. (ierm. Med. Mth.. 14: 405 (1969).

15. Kolvraa. S.: Inhibition of the glycine cleavage system by branched-chain amin، acid metabolites. Pediatr. Res.. 13: 889 (1979).

16. Krebs. H.: Discussion. In: P. A. Srere. R. W. Estabrook: Microenvironments ant Metabolic Compartmentation. p. 62 (Academic Press. Inc.. New York. 1978

17. Leitzmann, C.. Wu. J., and Boyer. P. D.: Subunits, composition, and relater properties of succinyl C'oenzyme A synthetase. Biochemistry. 9: 2338 (1970).

18. Mamunes, P.. DeVries, (;. H.. Miller. C. D.. and David. R. B.: Fatty acis quantitation in Reye's syndrome. In: J. D. Pollack: Reve's Syndrome. p. 24 (Grune \& Stratton. New York. 1974).

19. Nemeth. A. M.. Russell. C. S.. and Shemin. D.: The succinate-glycine cycle. II Metabolism of $\delta$-aminolevulinic acid. J. Biol. Chem.. 229: 415 (1957).

20. Pearson. D. J., and Tubbs. P. K.: Carnitine and derivatives in rat tissue. Biochem J.. 105: 953 (1967)

21. Rosenberg. L. E.: Disorders of propionate, methylmalonate, and cobalamir metabolism. In: J. B. Stanbury, J. B. Wyngaarden. D. S. Fredrickson: Th Metabolic Basis of Inherited Disease. Ed. 4. p. 411 (McCiraw-Hill Book (o. New York, 1978).

22. Rossi. C. R.. Alexandre. A.. Carignani. G.. and Siliprand. N.: Regulation mechanism for fatty acid and $\alpha$-ketoglutarate oxidations. Biochim. Biophys Acta. 234: 311 (1971).

23. Scarlato, G., Pellogrini. G.. Cerri, . .. Meola. G.. and Veicsteina. S.: The syndrom of carnitine deficiency: morphological and metabolic correlations in two cases Can. J. Neurol. Sci.. 5: 205 (1978).

24. Scrutton. M. D.. and White. M. D.: Purification and properties of human live pyruvate carboxylase. Biochem. Med.. 9: 271 (1974).

25. Soling H-D.: Anion transport through the inner mitochondrial membrane-site o regulation of gluconeogenesis? In: F. Lunguist. N. Tygstrup: Regulation o Hepatic Metabolism. p. 48 (Academic Press, Inc.. New York. 1974).

26. Stumpf, D. A.: Mitochondrial multisystem disorders. (linical. biochemical an morphological features. In: H. R. Tyler. D. M. Dawson: Current Neurology Vol. 2, p. 117 (Houghton Mifflin (o.. Boston. 1979).

27. Stumpf. D. A.. Mccabe. E. R. B.. Parks. J. K., Bullen. W. W.. and Schuft, S Loosely coupled mitochondrial oxidative phosphorylation induced by prote porphyrin. Biochem. Med.. 2I: 182 (1979).

28. Stumpf, D. A., and Parks, J. K.: rriedreich ataxia: I. Normal pyruvate dehy drogenase complex activity in platelets. Ann. Neurol., 4: 366 (1978). 
Stumpf, D. A., and Parks, J. K.: Friedreich ataxia: II. Normal kinetics of lipoamide dehydrogenase. Neurology, 29: 820 (1979).

Stumpf. D. A. and Parks. J. K.: Urea cycle regulation: I. Coupling of ornithine metabolism to mitochondrial oxidative phosphorylation. Neurology. 30: 178 (1980).

Tada. K.. Corbell. L. M., Eeckels, R., and Eggermont. E.: A block in glycine cleavage reaction as a common mechanism in ketotic and nonketotic hyperglycinemia. Pediatr. Res., 8: 721 (1974).

Trauner, D., Nyhan, W. L., and Sweetman, L.: Short-chain organic acidemia and Reye's syndrome. Neurology, 25: 296 (1975).

Trauner, D.. Sweetman. L., Holm, J., Kulovich, S., and Nyhan. W. L.: Biochem ical correlates of illness and recovery in Reye's syndrome. Ann. Neurol., 2: 238 (1977).

spyright (1) 1980 International Pediatric Research Foundation. Inc. $31-3998 / 80 / 1410-1127 \$ 02.00 / 0$
34. Walajtys-Rode. F. I.: Studies on the influence of fally acids on pyruvate dehydrogenase interconversion in rat liver. Eur. J. Biochem., 7l: 224 (1976).

5. The authors appreciate the helpful comments of Dr. Stephen Goodman.

36. Requests for reprints should be addressed to: Dr. David A. Stumpf, Director of Pediatric Neurology. Box (229. University of Colorado Health Sciences Center. 4200 East Ninth Ave.. Denver. (CO 80262 (USA)

37. This research was supported by a (linical Research Grant from the Muscular Dystrophy Association: NIH Program Project (irant HD 08315 and NIH (enter (jrant HD (44)24, both from NICHD

38. Received for publication November 13,1979.

39. Accepted for publication January 21. 1980 